\title{
The UNIfy program: \\ Providing Additional Support to Students \\ with Mental Health Issues in a University Context.
}

\author{
Jocelyn Courtney \\ UNIfy Coordinator and Counsellor \\ Student Wellbeing \\ University of the Sunshine Coast
}

\begin{abstract}
As student population numbers increase in tertiary institutions, so does the number of students presenting with diagnosed and undiagnosed mental health issues. According to the ABS (2008), $4.1 \%$ of the general population experience depressive episodes and $14.4 \%$ are diagnosed with anxiety disorders. However, students attending regional universities such as the University of the Sunshine Coast are at a greater risk of developing a mental illness due to factors such as social isolation, relocation and financial difficulties. A recent study (Mulder \& Cashin, 2015) indicated that $16 \%$ of the student cohort in a regional university in Australia presented in very high levels of distress. Considering the high volume of students presenting with mental health issues compared to the general Australian population, it is imperative that universities invest in the overall health of its students to improve retention rates, academic results, career outcomes, general wellbeing, and student satisfaction.

The following article demonstrates how the counselling team at the University of the Sunshine Coast provided additional support to students with mental health issues using a case-managed approach within the UNIfy program during the 2018 academic year.
\end{abstract}

\section{Keywords}

Mental health, mental illness, mental ill-health, case managed, psychological distress

\section{Background}

There is a paucity of Australian based research on the prevalence of mental illness within tertiary institutions, however overseas studies conducted by Eisenberg, Hunt and Speer (cited in Orygen, 2017), indicate that students, on average, tend to suffer poorer mental health outcomes than nonstudents. Studies conducted by Said, Kypri, and Bowman (2013) also reported a prevalence of depression at $8 \%$ and anxiety at $13 \%$ for Australian students compared to non-students at $4.1 \%$ and $14.4 \%$ respectively (ABS, 2008).

On a local scale, the University of the Sunshine Coast (USC) counselling team collected data on the number of students seeking support or presenting with mental health issues in semester two, 2017 with results demonstrating the most common presenting concerns were for anxiety (28\%), depression (18.9\%) and stress management issues (16.2\%). The AccessAbility team at USC also reported that $50 \%$ of students registered with their service have a mental health condition. Furthermore, estimates from USC's student experience team suggest that up to $80 \%$ of students on the Monitored Enrolment Program (MAP) specifically those on MAP $2 \&$ 3, would be experiencing some type of psychological distress.

These data however only captures the students who present to the suite of support services that are available to USC students, but inevitably there are students who have psychological barriers but have yet to access support on campus. Therefore, the real prevalence of mental ill health in the university student cohort is undoubtedly unknown. A study conducted by Stallman and Shochet (cited in Orygen, 2017) found that only 39\% of university students experiencing high levels of 
psychological distress sought professional assistance. Other limitations to accurate statistics include: students do not always choose to share information about their disability during the enrolment data collection phase (optional) and if they do, there is no provision to choose a disability type. Some students (both international and domestic) may be concerned about breaches of confidentiality. Students may be concerned that if they share information about their mental health diagnosis, this information could be communicated without their consent to academic staff which could have a detrimental impact on their grades or create a perception from the university that they do not have the capacity to undertake their studies or be suitable for their chosen profession.

Furthermore, USC has seen an increasing number of international students seeking support around psychological distress, but this is often done initially in the context of seeking support for extensions or advocacy around applying for a suspension of studies. In some cultures, is not unusual for mental illness to be unacknowledged or to have heavy stigma attached to it. Therefore, students often seek support when their academic success is jeopardised and not specifically for therapeutic counselling. Further, the widening participation of students from non-traditional backgrounds at USC (as recommended by the Bradley Review, 2008) are often students belonging to underrepresented sub groups. These students often require further scaffolding support in a university context to limit the incidence of onset of mental ill-health. Similarly, students with preexisting mental health issues may be at greater risk of crisis presentation if external personal stressors coupled with academic requirements exacerbate their condition.

\section{Description of initiative}

Evidence collected by Andrews and Wilding (2004) demonstrates that mental ill-health impacts negatively on academic performance and course completion rates. Consequently, the USC Counselling team acknowledged that there was a gap in service for vulnerable students where short term solution-focused counselling was not sought or deemed appropriate, with AccessAbility services unable to provide specific support to the needs of this group. UNIfy (UniForYou) closely aligns with USC's Strategic Plan Performance Measures 2016-2020 (USC, 2016) which focuses on (but is not limited to) the importance of student retention, student satisfaction, graduate outcomes and access to groups underrepresented in higher education. Similarly, the Student Engagement and Retention Blueprint 2017-2020 (Nelson, 2017) aims to strengthen first-year experiences, promote access, equity and diversity and enable support for learning (to name a few). UNIfy specifically addresses how a student's mental wellbeing impacts on their university experience and explores and implements ways to support students whilst they are at university.

The UNIfy program was developed and has been embedded within the counselling team's suite of programs since 2012. It has been delivered using various models of practice influenced by professional staff from the Student Wellbeing team during that time. It remained dormant for 12 months during the 2017 calendar year but was revamped to provide a more bespoke case managed approach to students. A casual staff member (.8FTE) from the counselling team was allocated 7.5 hours per week to dedicate to the operational delivery and oversight of UNIfy. Given the program was decommissioned for 12 months, demand was unknown. With limited resourcing, it was determined that the program would be given a soft launch, promoted internally to the Counselling and AccessAbility and Student Experience teams.

The program objectives are to:

- Work collaboratively with students to identify barriers as well as their strengths and needs.

- Create a "support plan" to address semester goals. 
- Focus on increasing confidence and knowledge of university resources to enhance adjustment to university life and improve help-seeking behaviours,

- Improve social connectedness to the university community, and

- Improve positive experiences and engagement at USC.

The UNIfy coordinator works from a strengths-based solution focused framework. Consistent, regular engagement is an important element of UNIfy as it ensures that students receive ongoing support and are less likely to disengage when they are struggling. Proactive follow up occurs when students fail to attend scheduled appointments. An initial 1-hour intake appointment is provided where a support plan is created at the commencement of support to ensure that the student's strengths and competencies are captured. In addition, goals are articulated to focus on what the student would like to achieve during the semester. This provides clear parameters around the type of support needed and how the UNIfy intervention will be focused. Goals generally pertain to attendance, participation, performance, belonging and social connectedness.

Another crucial element of the support plan is to ensure that the student's mental health experience is documented and their perception of how they may present if in distress is identified and recorded to mitigate and prevent further distress. The strategies utilised during episodes are listed and a response plan developed. Students provide consent for UNIfy to contact their external mental health providers to facilitate case consultation if required. Regular contact with the students is also important, as it is quite common, especially for students with anxiety and depression, to disengage and become discouraged. Weekly emails are sent out to UNIfy students to enhance connection and provide advice regarding campus activities, (organised by USC, Student Wellbeing or the Student Guild) as well as tips on study, time management, academic skills resources, self-care promotion and a motivational quote or humorous meme to conclude on a lighter note.

Appointments are generally provided on a fortnightly basis (for half an hour) where the student briefly discusses the assessments they are currently working on and any barriers they may be having. Resources are recommended, (such as academic skills or drop-in study groups) emotional wellbeing is briefly explored and strategies around self-care are reinforced. The support plan is also referred to on a regular basis to ensure the intervention is targeted and on track.

\section{Evaluation used}

It was essential to capture qualitative data from the students directly involved with the program. Therefore, feedback was sought to gather information about whether they felt supported, whether the time allocated to them was adequate, if they thought their grades improved because of the support received and whether the support plan helped maintain their focus on their semester goals to name just a few. At the completion of the survey, students were asked to rate the program out of five stars. The results from students provided positive feedback about the program as well as a four and a half star rating out of five. Furthermore, enrolment data were analysed at the end of semester one to determine whether students were still enrolled and continuing with their courses (to determine retention rates), and academic achievement results (GPA) were examined to gauge student academic performance.

\section{Outcomes}

The students supported by UNIfy in 2018 provided positive feedback about the program. Some students remained involved over the two semesters, whilst others have exited the program. Some of the reasons for exit include taking a leave of absence, returning to their home country or feeling 
sufficiently capable of navigating university on their own. The enrolment data showed that $86 \%$ of the students that received UNIFy support, remained enrolled thus demonstrating a lower than average attrition rate of $14 \%$ compared with the QLD University average at $15.72 \%{ }^{1}$ (Australian Government Department of Education and Training, 2016). Of the students who studied in the previous semester, 61\% improved their GPA and 100\% of newly enrolled students passed their courses in semester one. Furthermore, students felt that they were much more aware of the support services widely available on campus and this is reflected by the fact that no UNIfy students presented in crisis to Student Wellbeing during semester one. Inference is made that if the student's mental health is acknowledged, supported and stable, then they are more likely to attend classes, undertake assessments and remain engaged with wider university supports, thus increasing the likelihood of a successful university experience.

\section{Challenges and limitations}

At semester peak, the UNIfy coordinator was supporting up to 23 students concurrently. This presented challenges with the 7.5 hour per week staffing allocation. Apart from providing face-toface appointments, students often required additional support including liaison with academic staff, provision of supporting evidence for extensions or retrospective course withdrawal, advocacy to amend student learning access plans with the AccessAbility team and general telephone or email support when students failed to attend scheduled appointments. Another challenge was supporting students with ASD. The students in this cohort were often referred to UNIfy due to their secondary condition of anxiety, but it was apparent that the cognitive and social barriers they faced required a more specialised service. Furthermore, a small percentage of students found it difficult to satisfy the course requirements and did not attain their desired grades. Even with all the resources provided by the university (including reasonable adjustments) some students will continue to face barriers and find university study demanding; these students however have found university to be a nurturing and supportive environment where they have found a sense of purpose, belonging and social connection. This leads, however to an ethical dilemma needing further dissection and discussion.

\section{Conclusion}

The relaunch of UNIfy at USC has proved to be overwhelmingly successful. The stakeholders (referrers, students and the coordinator) have found it to be a highly worthwhile and beneficial program for the students involved. Students have provided regular, positive feedback about their participation in the program and many are hoping to continue their involvement. Overall, it has resulted in a reduction of crisis presentations and an increase in retention rates, improvement of student academic progress and an overall sense of satisfaction and connection by students to the USC community. It would be highly desirable for UNIfy to continue in 2019 and for it to be accompanied with further funding to expand its reach to support more students in the future.

\footnotetext{
${ }^{1}$ New Adjusted Attrition rate. Australian Government Department of Education and Training (2016). 2016 Appendix 4- Attrition, success and retention. 


\section{References:}

Andrews, B, \& Wilding, J.M. (2004). The relation of depression and anxiety to life-stress and achievement in students. British Journal of Psychology, 95, 509-521.

Australian Bureau of Statistics (2008). 2007 National survey of mental health and wellbeing: Summary of results (No: 4326.0) [Online]. Retrieved from: http://www.abs.gov.au/

Australian Government. (2008). Review of Australian Higher Education: final report (Bradley Review). Retrieved from:http://www.voced.edu.au/content/ngv\%\#A32134

Australian Government Department of Education and Training (2016). 2016 Appendix 4-Attrition, success and retention. Retrieved from: https://docs.education.gov.au/documents/2016-appendix-4-attrition-success-andretention

Mulder, A., \& Cashin, A. (2015). Health and wellbeing in students with very high psychological distress from a regional Australian university. Advances in Mental Health: Promotion and Prevention and Early Intervention, 13(1),72-83.

Nelson, K. (2017). USC student engagement and retention blueprint 2017-2020. Retrieved from: https://my.usc.edu.au/_layouts/15/WopiFrame.aspx?sourcedoc=/Documents/Student\%20Engagement\%20and \%20Retention\%20Blueprint\%202017-2020.pdf\&action=default

Orygen, The National Centre of Excellence in Youth Mental Health (2017). Under the radar: The mental health of Australian university students. Melbourne: Orygen, The National Centre of Excellence in Youth Mental Health.

Said, D., Kypri, K., \& Bowman, J. (2012) Risk factors for mental disorder among university students in Australia: Findings from a web-based cross-sectional survey. Social Psychiatry and Psychiatric Epidemiology, 48, 935944.

University of the Sunshine Coast. (2016) University of the Sunshine Coast strategic plan 2016-2020. Retrieved from: https://www.usc.edu.au/media/16940445/usc-strategic-plan-2016-2020_final_web_v3.pdf

The author may be contacted:

jcourtne@usc.edu.au

\section{Please cite this paper as:}

Courtney, J. (2018). The UNIfy program: Providing additional support to students with mental health issues in a university context. Journal of the Australian and New Zealand Student Services

Association, 27(1). 62-66. doi.org.10.30688/janzssa.2019.01 